\title{
O whatsapp como ferramenta educativa de participación e de aprendizaxe da lingua galega e a súa didáctica
}

\author{
Mosquera Castro, Estefanía \\ Universidade da Coruña, Facultade de Ciencias da Educación
}

\section{RESUMO}

A proposta educativa que se presenta é unha experiencia práctica levada a cabo no curso académico 2016/2017 na materia "Lingua galega e a súa didáctica" de primeiro curso do grao en Educación Primaria da Facultade de Ciencias da Educación da Universidade da Coruña. Consiste na creación dun grupo de Whatsapp ao inicio de curso en que figure tanto 0 alumnado como o profesorado da materia e no que os participantes aceptan como norma tácita 0 uso do galego co obxectivo de consolidar a súa praxe en lingua galega e de motivar e implicar o alumnado na materia. A súa implementación permitiu verificar as posibilidades pedagóxicas que ofrece a aplicación na área da didáctica das linguas para ambos os colectivos: ao alumnado o grupo concédelle máis un foro para mellorar a súa competencia lingüística e, ao tempo, fomenta o interese pola materia ao ser abordada nunha linguaxe en que se sente cómodo, polo que tamén participa con maior profusión; á docente permítelle ter un maior volume de información para avaliar o alumnado e paliar as limitacións temporais dunha materia cuadrimestral ao non restrinxir a aprendizaxe ao horario académico, o que tamén posibilita diluír as fronteiras entre a educación formal e non formal.

PALABRAS CHAVE: Whatsapp, didáctica da lingua galega, comunicación escrita, participación. 


\section{CITA RECOMENDADA:}

Mosquera Castro, E. (2018). 0 whatsapp como ferramenta educativa de participación e de aprendizaxe da lingua galega e a súa didáctica. En E. de la Torre Fernández (ed.) (2018). Contextos universitarios transformadores: retos e ideas innovadoras. II Xornadas de Innovación Docente. Cufie. Universidade da Coruña (páx. 63-80).

DOl capítulo: https://doi.org/10.17979/spudc.9788497496780.063

DOl libro: https://doi.org/10.17979/spudc.9788497496780

\section{ABSTRACT}

The educational proposal shown in this project is a practical experience carried out during the academic year 2016/2017 in the subject "Galician language and its teaching" of the first course of Primary Education degree in the faculty of Educational Sciences at the University of A Coruña. It consists on the creation of a WhatsApp group at the beginning of the course where it is included the students as well as the professor of the subject and where the participants accept as a tacit rule the use of Galician language with the objective of consolidating their praxis in Galician language and motivating and involving the students in the subject. Its implementation allowed to verify the pedagogical possibilities offered by the application in the area of language teaching for both groups: for the student body the group is, above all, a forum to improve their linguistic competence and, at the same time, it increases their interest on the subject as it is addressed in a language which they feel comfortable with. Therefore, they also take part more frequently; for the teacher it allows to have a higher volume of information to evaluate the students and reduce temporary limitations in a four-month subject, as it does not restrict the learning to the academic schedule, which makes also possible to reduce the limits between conventional and non-conventional education.

KEY WORDS: Whatsapp, Galician language teaching, written communication, participation. 


\section{INTRODUCIÓN}

Nos últimos tempos estamos sendo testemuñas dunha revolución tecnolóxica sen precedentes que nos sitúa nun novo escenario social en que até aquelas estruturas sobre as que décadas atrás se tiña absoluto convencemento se transforman. Estas mudanzas foron especialmente transcendentais no ámbito da comunicación electrónica en que se alteraron as barreiras tradicionais de espazo e tempo ao permitir que as persoas puidesen interaxir con independencia das limitacións xeográficas e horarias que as puideren afastar, o que mudou de forma irrefutábel os nosos hábitos de vida. Por tanto, xulgamos que non se trata só dunha transformación tecnolóxica que altera o modo en que nos comunicamos, mais sobre todo dunha auténtica metamorfose social; e neste sentido concordamos con Moura \& Carvalho (2010:1001) en que "sendo a escola um pilar no seio das revoluções sociais, tecnológicas e económicas, são numerosas as transformações a desafiá-la".

$\mathrm{Na}$ actualidade os dispositivos móbeis viraron elementos imprescindíbeis no día a día das persoas -en especial das máis novas- e revolucionaron os hábitos de traballo e de aprendizaxe ao abriren múltiplas posibilidades, tamén na esfera educativa. Así, 0 desenvolvemento tecnolóxico incrementou e diversificou as prácticas letradas para aprender nas distintas materias e disciplinas, con artefactos didácticos sofisticados e específicos para cada materia (Cassany, 2012:248) cos que xa contan moitos centros de ensino e que tamén se incorporan ao currículo. Con todo, este tipo de iniciativas relacionadas coas tecnoloxías da información e da comunicación (TIC) son formuladas fundamentalmente en clave tecnolóxica e desatenden en moitos casos a perspectiva pedagóxica, de forma que nin sempre se acompañan de novas aptitudes e enfoques metodolóxicos para encarar desde esta óptica 0 proceso de ensino-aprendizaxe.

Nesta liña, non basta só con integrarmos as TIC nas aulas, mais igualmente e sobre todo de conseguir que estas potentes ferramentas de información e de comunicación se tornen tamén en tecnoloxías da aprendizaxe e do coñecemento (TAC) e se configuren, así, nun instrumento de inclusión dixital, nun recurso para a aprendizaxe e nun axente de innovación educativa. 
Mais como apunta Sancho Gil (2008:20), pasar de TIC a TAC implica moito máis que 0 cambio dunha simple vogal, pois obriga ao ensino a se adaptar aos novos tempos, ás novas necesidades e ao perfil do alumnado actual. En consecuencia, é preciso que os docentes respondan a través de novas propostas metodolóxicas ás mudanzas cognitivas do seu alumnado para, deste modo, deixar de ensinar nunha lingua obsoleta (a da era predixital) a un sector da poboación que fala nun idioma totalmente novoii (Mosquera Castro, 2015a:394).

E desde unha perspectiva didáctica, vira absolutamente necesario que os docentes sexan capaces de apropiarse destas ferramentas e tirarlles a maior rendibilidade no marco educativo, en lugar de disuadir o alumando do seu uso nas aulas (Moura \& Carvalho 2010:1001); isto, na nosa opinión, non supón alterar o significado do que é ou non é importante mais si garantir unha formación que ofreza ao alumnado a posibilidade de integrar nas aulas estas prácticas de aprendizaxe, especialmente se permiten que esta vire máis atractiva e que perdure. Como apunta Cassany (2012:250), hoxe en día a educación formal nas aulas ten que considerar 0 que acontece fóra das paredes escolares e, en consecuencia, debe identificar e valorar as aprendizaxes que se realizan na rede e trazar pontes entre as prácticas académicas e as vernáculas, sobre todo se estas multiplican exponencialmente as posibilidades de acceder ao coñecemento. Deste modo, será tamén posíbel diluír as fronteiras entre a educación invisible e o currículo oculto -en tanto que non se recoñece- e a formación regrada (Cobo \& Moravec 2011:26).

Outrosí, a introdución destas ferramentas en clave pedagóxica non se limita só a (r)evolucionar o que acontece dentro das aulas; segundo Alexander (2004), a aplicación das tecnoloxías móbiles na educación tamén favorece que se dilaten as súas fronteiras, na medida en que permite ligar profesorado e alumnado dentro e fóra da sala de aula e proporcionar unha experiencia formativa cada vez máis ubicua e interconectada coas aprendizaxes que se producen noutros contextos. Desde este prisma vira moito máis sinxelo que os centros de ensino se transformen en lugares que axudan "a los aprendices a integrar los aprendizajes que 
suceden en los otros ambientes. Es decir que sigue ocupando un rol central, pero nuevo y diferente al tradicional" (Gvirtz \& Necuzzi, 2011:22).

Esta nova concepción avanza máis un paso en tanto que percibe estes instrumentos non só como simples recursos educativos, senón tamén como tecnoloxías para o empoderamento e a participación (TEP) entre alumnado e docentes. De acordo con Cabero Almenara (2015:23), desde este marco a aprendizaxe ten unha dimensión máis social e colectiva do que individual e unidireccional e, por tanto, para a formación é tamén preciso saber aprender en comunidade e ser capaz de colaborar e interactuar para construír o coñecemento. Nestes medios resulta doado reparar tanto no impacto que a rede tivo nos usos escritos como nas posibilidades que as novidades tecnolóxicas ofrecen como instrumentos educativos de participación e de aprendizaxe para 0 ensino de linguas:

El tiempo que los chicos pasan conectados tiene mucha incidencia en su vida y educación. Si un chico actualiza su perfil en una red social cada día, escribiendo un comentario breve en su muro, visitando los de sus amigos y respondiendo algún mensaje breve, aunque sean unos pocos minutos acaban siendo muchas horas al año. Si una chica chatea con los amigos una hora al día, es mucha la información que aprende, la práctica que desarrolla y la empatía que consolida con sus interlocutores (Cassany, 2012:91-92)

Estamos, en todos os casos citados, perante prácticas letradas que ocorren no ámbito privado e de lecer, que non son impostas -en tanto que as facemos por vontade propia- e que nos resultan interesantes desde unha perspectiva social. Non obstante, tenden a ser deostadas e ignoradas, ou cando menos marxinadas, na esfera educativa, a pesar do potencial que presentan no proceso de ensino-aprendizaxe, na medida en que contribúen tanto para a adquisición de contidos, como para que 0 alumnado vexa que as aulas de lingua reflicten tamén 0 que os falantes fan co idioma fóra delas e tamén para aumentar a motivación e implicación na materia. 
E, nesta liña, pensamos que a inclusión deste tipo de prácticas no marco das aulas tórnase moito máis necesaria cando o idioma obxecto da aprendizaxe non coincide coa primeira lingua (L1) do alumnado, pois para alén do factor motivacional ofrécelle tamén outros espazos ademais dos académicos- en que adquirir, reforzar ou mellorar a súa competencia lingüística desde unha óptica eminentemente comunicativa e funcional que, no caso das $L 1$, xa vén dada polo resto do contorno que rodea 0 alumno, tamén 0 escolar, mais fundamentalmente 0 familiar e o mediático (Mosquera Castro, 2015b:15).

A formación docente do profesorado, e en particular daquel que imparte materias lingüísticas, non debe -desde o noso punto de vista- permanecer alleo a esta realidade e, en consecuencia, nas páxinas que seguen reflectiremos sobre as posibilidades educativas dos sistemas de comunicación electrónica para 0 ensino de linguas a partir dunha experiencia concreta que se realizou a través da aplicación Whatsapp. E aínda que se centra de forma específica na lingua galega, xulgamos que as súas potencialidades son perfectamente extrapolábeis a outros contextos lingüísticos.

\section{DESCRICIÓN DA EXPERIENCIA}

A materia "Lingua galega e a súa didáctica" en que ten lugar a experiencia impártese no $1^{0}$ Cuadrimestre, do $1^{0}$ curso do grao en Educación Primaria da Facultade de Ciencias da Educación da Universidade da Coruña. Por unha banda, o perfil do alumnado é maioritariamente castelanfalante e, infelizmente, as medidas lexislativas que na teoría amparan o uso e a normalización do galego no ámbito educativo non universitario non contribúen para reforzar a competencia do alumnado neste idioma, mais ao contrario impiden que este acade unha competencia comunicativa minimamente aceptábel e comparábel coa que teñen en español, a pesar de ser este o obxectivo que se defende (Callón, 2011). Outrosí, a nosa experiencia docente tamén nos permite corroborar que este nivel certamente baixo e nalgúns casos nulo de competencia en lingua galega está tamén presente non só no alumnado que 
inicia os seus estudos universitarios, mais en moitos casos tamén no que os finaliza e que na teoría está capacitado para exercer a docencia neste -e tamén deste- idioma.

Así, encontrámonos con estudantado que non chega ao ensino universitario coas competencias lingüísticas que se lle presupoñen, o que, tal é como xa se indicou en Mosquera Castro (2015b:13), acaba por se converter nun dilema relevante para 0 docente de didáctica en lingua galega: de que modo nos podemos centrar no como cando non se sabe 0 que? $\mathrm{E}$, por outra banda, a isto cómpre sumarmos tanto as limitacións derivadas da falta de tempo para acometer o proceso de ensino aprendizaxe nunha materia cuadrimestraliii, como o feito de que ao non ser un grao de especialización filolóxica os intereses do alumnado poden non ser sempre afíns ás áreas lingüísticas ou á da lingua galega en particular, pola súa condición de lingua minorizada.

Neste sentido, pensamos que a nosa proposta pode dar resposta, cando menos parcialmente, ás dúas carencias sinaladas até agora, na medida en que promove unha transformación metodolóxica na didáctica da lingua incorporando as TIC como espazo de participación democrática e de aprendizaxe, que desbota a idea de que a tecnoloxía constitúe unha distracción no proceso de aprendizaxe e que ofrece un novo escenario que transcende 0 espazo físico e temporal das aulas e que ademais ten un impacto inmediato no alumnado, 0 que amplía as posibilidades de mellorar, reforzar ou consolidar tanto a competencia lingüística do alumnado como os contidos didácticos da materia.

En concreto, a proposta educativa que se presenta é unha experiencia práctica que se levou a cabo como proxecto piloto no curso académico 2016/2017 e que tivo continuidade no 2017/2018 e consiste na creación dun grupo de Whatsapp ao inicio de curso en que figure tanto 0 alumnado como o profesorado da materia e no que os participantes aceptan como norma tácita o uso do galego para debater, comentar ou reflexionar sobre diferentes cuestións que acontecen fóra das aulas e que poden ser de interese, ben por permitiren ilustrar 0 analizado nas aulas, ben por repercutiren directamente nos propios contidos e no modo de os abordar desde unha perspectiva didáctica. 
0 alumnado é 0 encargado de crear 0 grupo de Whatsapp e de lle buscar un título e unha imaxe que deciden entre todos e que pode ir mudando ao longo do curso. Como resultado son dous os grupos que se crean para cada curso, pois son tamén dous os grupos de aula nos que se imparte a materia ( $\mathrm{e}$ e $B$ ); como entre eles non se coñecen, inicialmente consideramos oportuna esta división para contribuír a consolidar as relacións entre os membros de cada un que, en moitos casos, ao se dividiren continuamente en pequenos grupos interactivos non sempre teñen demasiadas oportunidades para interaxir entre todos. Nese sentido, esta experiencia ofrécelles máis un espazo, que ademais conta coa mediación da docente. Con todo, conviría tamén explorar no futuro a posibilidade de fomentar as relacións entre os dous grupos ( $A$ e B) coa finalidade engadida de crear, aínda que sexa virtualmente, unha identidade común, unha consciencia de promoción, na medida en que partillan intereses, coñecementos, proxectos e propósitos.

Mais para alén destas cuestións que non deixan de ser accesorias ou complementarias, os obxectivos concretos aos que pretende contribuír esta experiencia son dous e son específicos da disciplina para a que se crea: por unha banda, consolidar a praxe do alumnado en lingua galega e por outra motivar e implicar o alumnado na materia. E en liñas xerais, consideramos que os resultados obtidos neste tempo -como veremos na seguinte sección- permiten afirmar non só que se cumpriron os obxectivos específicos que a motivaron, senón tamén que esta dinámica coadxuva igualmente na consecución dos que a propia materia estabelece, isto é, capacitar 0 alumnado para desenvolver 0 ensino-aprendizaxe da lingua galega tanto a través dunha formación didáctica apropiada para o contexto lingüístico deste idioma como do reforzo da súa competencia comunicativa, para que poidan constituírse en verdadeiros modelos pedagóxicos e lingüísticos.

\section{RESULTADOS}

Os dous cursos académicos en que esta iniciativa tivo lugar permitiron observar as diversas potencialidades que 0 uso do whatsapp presenta como ferramenta educativa de participación 
e de aprendizaxe da lingua galega e da súa didáctica desde varias perspectivas complementarias. A primeira delas ten que ver coa vantaxe que este instrumento ofrece para paliar en certo modo as carencias que as limitacións temporais dunha materia cuadrimestral presenta para a adquisición e para a consolidación do coñecemento que, como é evidente, se adquire coa práctica e exixe tempo e condicións adecuadas. Así, a aprendizaxe non se restrinxe unicamente ao horario académico, mais ao contrario, convértese nun foro multidireccional as 24 horas, como se pode comprobar nas imaxes que se inclúen nesta epígrafe, que na maior parte dos casos exceden os tempos en que ten lugar a docencia presencial.

A segunda delas está relacionada coas posibilidades que esta ferramenta lle ofrece ao alumnado para reflexionar, procesar, compartir e relacionar a información que a respecto da materia se produce tanto dentro como fóra das aulas. Así, na imaxe 1 pódese observar como o alumnado que nese momento asistía a unhas xornadas de animación á lectura non só participaba de forma presencial formulándolle ao poñente preguntas que enfiasen 0 seu discurso, mais ao tempo, estaba tamén a interaccionar virtualmente comentando o que lle estaba a parecer a conferencia e relacionando o que nela se dicía con contidos puramente curriculares que acababan de ser traballados nas aulas, como é o caso do lugar e a función da gramática no ensino-aprendizaxe dunha lingua. 


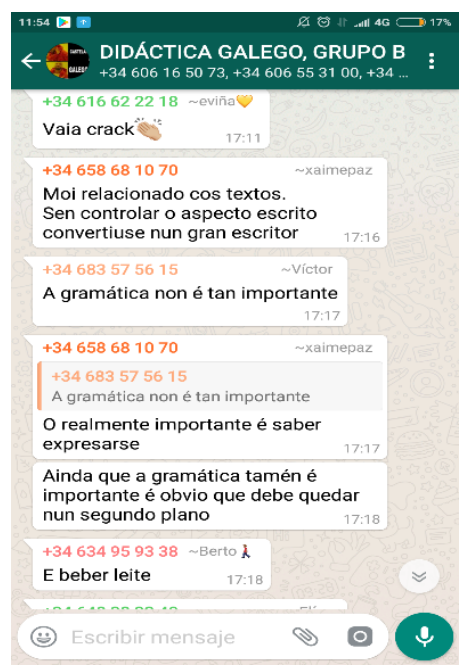

Imaxe 1. Exemplo de reflexión sobre a materia

Ao mesmo tempo, esta forma de encarar o proceso de ensino-aprendizaxe ao ser abordado desde unha linguaxe -a dixital- e un soporte -as TIC- que tamén é o seu e onde se sente cómodo, fomenta o interese do alumnado pola materia, o que se desprende do alto grao de participación e de achegas a través do grupo. Sirva como exemplo a imaxe 2, que constitúe 0 inicio dunha conversa que se iniciou logo de que unha alumna colgase unha foto dun panel que contiña un poema en lingua galega un día en que os incendios asolagaron a Galiza. 0 contido do texto ("Lonxe de ti miña terra teño que marchar mais nos teus verdes montes espero cedo espertar...") fixo que axiña comezasen a interaxir entre eles sobre 0 que estaba a acontecer; así, unha conversa que comezou na tarde dun domingo prolongouse até a madrugada do día seguinte e permitiu contabilizar máis de 200 intervencións. 


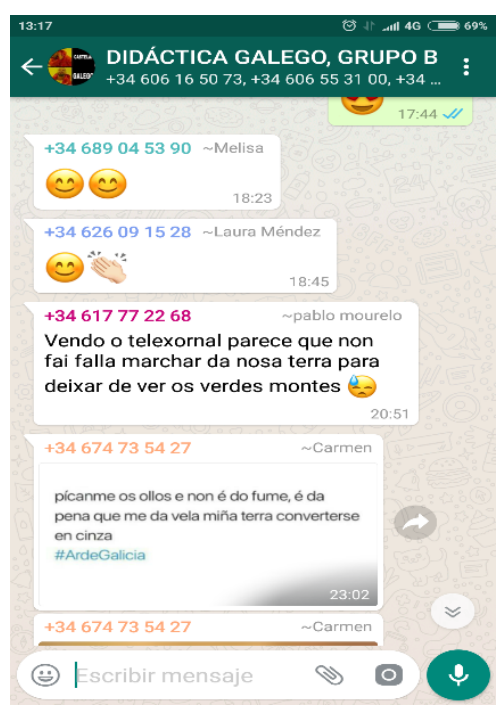

Imaxe 2. Mostra do grao de participación

Neste sentido, o propio desenvolvemento da dinámica permite ao alumnado analizar as posibilidades que a nivel metodolóxico presenta 0 uso das TIC no ensino-aprendizaxe dunha lingua e, en particular da galega, non só desde unha perspectiva tecnolóxica, mais fundamentalmente didáctica: por un lado, porque a distancia entre os participantes especialmente entre alumnado e docente- e 0 modo en que se produce a comunicación facilita a participación ás persoas máis introvertidas que non sobresaen nas interaccións presenciais (Vázquez Simarro 2016:195); e por outro lado, porque a propia participación no grupo concede ao alumnado máis un foro en que desenvolver e mellorar a súa competencia lingüística, tanto a través da autocorrección como da retroalimentación dos seus iguais e/ou da docente, como se observa na imaxe 3. 


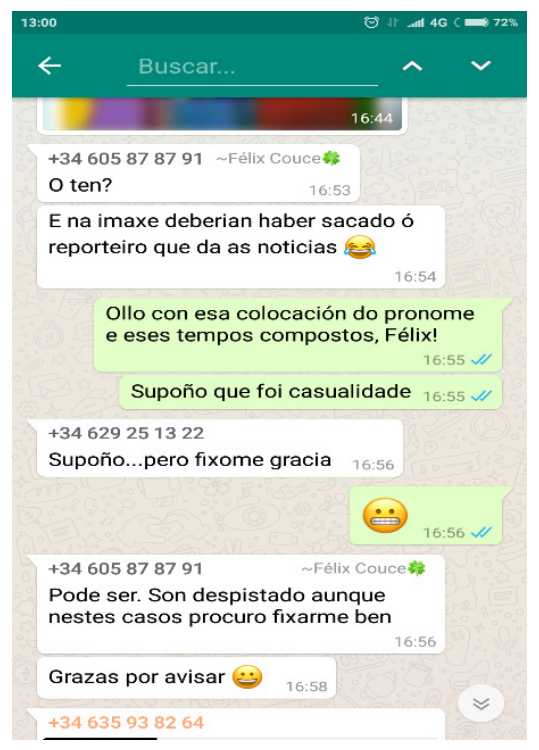

Imaxe 3. Caso de corrección lingüística

A filosofía que, na realidade, se encontra tamén detrás desta iniciativa ten como finalidade que as accións comunicativas, dialóxicas ou multimodais se constitúan como máis un elemento central do proceso de ensino-aprendizaxe, non só na medida en que contribúen ao intercambio lingüístico e a mellorar a competencia escrita e oral do alumnado, mais sobre todo porque se parte da hipótese de que os propios descritores da materia poden ser cuestionados e discutidos de forma conxunta e construír así o que Apple e Bean (2000) denominan un currículo democrático. Neste caso, a situación en que se encontra a lingua galega é unha realidade social moi próxima ao noso alumnado, aínda que non sexa a súa primeira lingua e isto permite que moitas veces tome a iniciativa á hora de propor temas de debate ou de continuar con aqueles que se produciran previamente nas aulas.

Deste modo, no grupo debátense e compártense problemáticas sociolingüísticas que acontecen fóra das aulas e que afectan á didáctica do galego: e se ben na maioría dos casos estas serven para exemplificar cuestións traballadas nas aulas, como pode ser a constatación de que aínda permanecen determinados prexuízos a respecto do galego ou a vulneración de 
determinados dereitos lingüísticos, noutros casos mesmo rectifican ou transforman os propios contidos que se imparten de forma presencial, como se pode ver na imaxe 4.

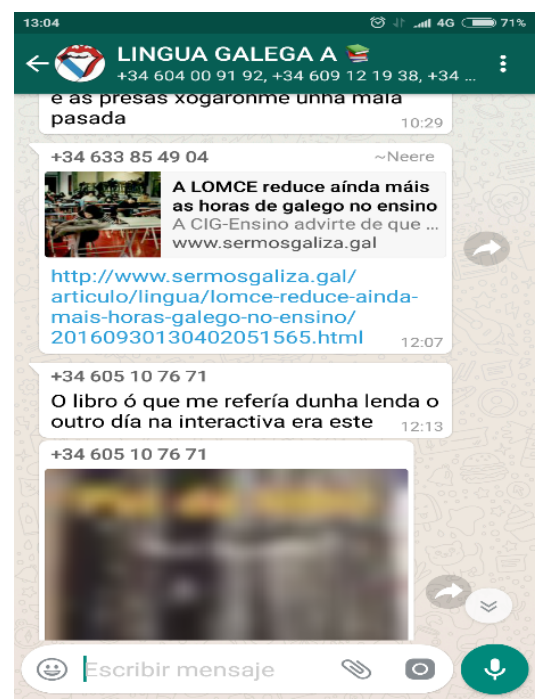

Imaxe 4. Tipo de contribución do alumnado

Outrosí, o grupo é tamén 0 espazo en que 0 alumnado aproveita para partillar as súas impresións sobre os experimentos sociolingüísticos que se realizan fóra das aulas e que, na nosa opinión, lle permiten consolidar os contidos de forma máis significativa, ao involucralos no proceso de aprendizaxe e convertelos en protagonistas de cada acción (Fernández Rial, 2014:85). De feito, nuns casos estas experiencias son formuladas pola docente, mais noutros son eles e elas as artífices das propostas, mais ambas as opcións teñen en común que a participación é voluntaria, como voluntario é tamén 0 grao de implicación no grupo de Whatsapp. Con todo, parece que o enfoque participativo e dialóxico que se lle dá á materia, contribúe non só para que todas as propostas teñan unha moi boa acollida -como se aprecia na imaxe 5-, mais tamén para que se retroalimenten entre elas, o que coadxuva na formación do alumnado para o desempeño da súa actividade profesional, mais tamén para a vida, fomentando nel competencias cívicas. 


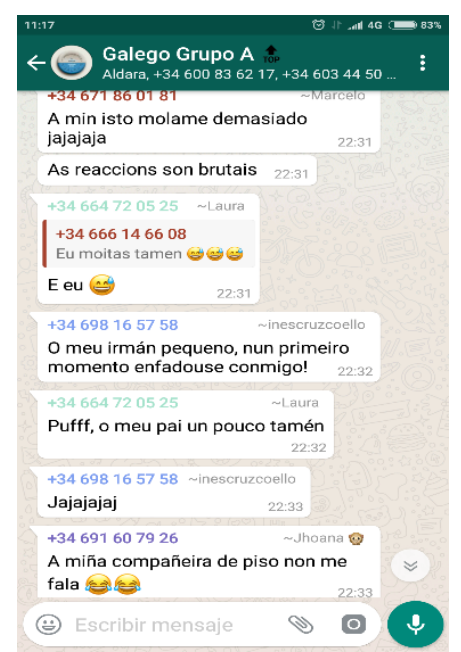

Imaxe 5. Extracto das valoracións das experiencias

En definitiva, concordamos con Cobo \& Moravec (2011:26) en que os docentes ensinamos máis do que podemos avaliar e en que non todo 0 que 0 alumnado aprende é necesariamente recoñecido como aprendizaxe dentro da educación formal. Con todo, esta experiencia permite verificar que mentres máis ubicuas e diversas sexan as ferramentas que apoian o proceso de ensino-aprendizaxe, máis probábel é que as habilidades e as aprendizaxes invisíbeis para os instrumentos que tradicionalmente miden o coñecemento se poidan tamén constatar; e o certo é que 0 grupo de whatsapp permite á docente obter un maior volume de información dificilmente cuantificábel con outro tipo de ferramentas- para valorizar as contribucións do alumnado e o seu grao de compromiso coa materia.

\section{CONCLUSIÓNS}

0 nivel de participación do alumnado superou en ambas as edicións as expectativas iniciais e, de feito, parte das persoas que integraban o grupo do curso 2016/2017 continuaban facendo achegas un cuadrimestre despois de seren avaliadas, o que desde 0 noso punto de vista contribúe para avalar positivamente esta experiencia. Así mesmo, as valoracións do alumnado foron, de momento, sempre favorábeis, non só a respecto da mellora dos seus coñecementos 
sobre didáctica ou da súa competencia comunicativa, mais tamén no tocante a cuestións puramente organizativas ou sociais, o que reforza a nosa idea de continuarmos con esta experiencia na medida en que consideramos que supón unha aproximación didáctica actualizada e próxima á realidade do alumnado, un alumnado que demanda metodoloxías que lle permitan formarse en consonancia cos novos tempos e coas necesidades actuais da sociedade e da cidadanía.

Involucremos, pois, ao alumnado no seu propio proceso de aprendizaxe e exploremos como docentes 0 que este fai fóra das aulas para conectar o currículo académico coa súa aprendizaxe informal; fagámola visíbel e experimentemos -con curiosidade e sen prexuízosas posibilidades que as novas prácticas letradas produto da tecnoloxía ofrecen desde unha perspectiva didáctica. Atrevámonos a probar novas metodoloxías que fagan posíbel a mellora educativa ou, cando menos, asegurémonos coa práctica de que non estamos a servir 0 mesmo viño en copas novas (Cassany, 2012:270).

\section{REFERENCIAS}

- Alexander, B. (2004). Going Nomadic: Mobile Learning in Higher Education. EDUCAUSE Review, 39 (5), pp. 28-35.

- Apple, M. W. \& Beane, J. A. (2000). Escuelas democráticas. Madrid: Morata.

- Cabero Almenara, J. (2015). Reflexiones educativas sobre las tecnologías de la información y de la comunicación (TIC). Revista Tecnología, Ciencia y Educación, 1, pp.19-27.

- Callón, C. (2011). Como defenderes os teus dereitos linguísticos. Vigo: Xerais.

- Casanny, D. (2012). En_línea. Leer y escribir en la red. Barcelona: Anagrama.

- Cobo, C. \& Moravec, J. W. (2011). Aprendizaje invisible. Hacia una nueva ecología de la educación. Barcelona: Universitat de Barcelona.

- Fernández Rial, R. (2014). Aproveitamento do teatro na aprendizaxe da lingua. En C.C. Biscainho Fernandes \& X. R. Freixeiro Mato (eds.), Lingua e Teatro. X Xornadas sobre 
Lingua e Usos (pp. 71-87). A Coruña: Servizo de publicacións da Universidade da Coruña.

- Gvirtz, S. \& Necuzzi, C. (eds.) (2011). Educación y tecnologías. Las voces de los expertos. Buenos Aires: Anses.

- Mosquera Castro, E. (2015a): A didáctica da lingua e da literatura no marco das TIC: novos códigos e novas aproximacións. En X. Núñez Sabarís \& A. González Sánchez \& C. Pazos Justo \& P. Dono López (eds.), Horizontes científicos y planificación académica en la didáctica de lenguas y literaturas (pp. 393-407). Ribeirao: Humus.

- Mosquera Castro, E. (2015b). A formación do profesorado de lingua galega: perspectivas pedagóxicas e modelo lingüístico. Revista de Estudios e Investigación en Psicología y Educación, 6, pp.12-16.

- Moura, A. \& Carvalho, A. (2010). Enquadramento teórico para a integração de tecnologias móveis em contexto educativo. En F.C. Costa (org.), Actas do Encontro Internacional TIC e Educação I (pp.1001-1006). Lisboa: Instituto de Educação da Universidade de Lisboa.

- Sancho Gil, J. M. (2008). De TIC a TAC, el difícil tránsito de una vocal. Investigación en la escuela, 64, pp.19-30.

- Vázquez Simarro, M. (2016). Integración de Whatsapp en la enseñanza de español como segunda lengua. Propuesta de b-learning. En III Jornadas Iberoamericanas de Innovación Educativa en el ámbito de las TIC. Disponíbel en https://acceda.ulpgc.es/bitstream/10553/20467/1/0730076_00000_0028.pdf [consult. 24/11/2017].

\footnotetext{
' Nestes medios, destaca a inclusión da alfabetización dixital como unha das oito competências básicas nas últimas leis educativas promulgadas polo estado español (LOCE, LOE E LOMCE).

ii Na opinión de Cassany (2012:270), "habrá que revisar los currículos cerrados y centrados en contenidos locales, las clases magistrales y los ejercicios mecánicos de repetición, las tareas "fuera de línea" o que evitan acceder a la red, los trabajos individuales que prohíben interactuar con los colegas".
} 
iii Sobre este particular, convén tamén ponderarmos que no grao en Educación Primaria 0 alumnado tan só dispón de 12 créditos para abordar a didáctica da lingua e da literatura galega, 0 que resulta insuficiente para os formar desde a perspectiva pedagóxica e para solventar as carencias que arrastran e que lles impiden converterse en referentes lingüísticos para o seu futuro alumnado. 